\title{
Foreign Aid and Government Legitimacy
}

\author{
Simone Dietrich \\ (University of Missouri) \\ Matthew S. Winters \\ (University of Illinois Urbana Champaign)
}

July 19, 2014

\begin{abstract}
Branding of foreign aid may undermine government legitimacy in developing countries when citizens see social services being provided by external actors. We run a survey experiment on a sample of Indian respondents. All subjects learn about an HIV/AIDS program; treated subjects learn that it was foreign-funded. Although the results are not statistically significant at conventional levels, the patterns in the data suggest that approval ratings for key government institutions are lower in the treatment conditions while assessments of government performance are higher. These contrasting effects point toward the multiple ways in which government legitimacy might be affected by the presence of foreign aid: political representatives might suffer reputational loss, while overall state legitimacy remains unchanged.
\end{abstract}


The literature on the "fiscal contract" proposes that states trade public service provision in exchange for tax payments and other forms of compliance from their citizens (Bates and Lien 1985; Levi 1988; Timmons 2005; Moore 2008). In aid-dependent developing countries, however, the state may not be the actor providing the basic services and public goods that citizens use, and this may have implications for the strength of the fiscal contract. In recent years, international donors and non-governmental organizations have placed increasing emphasis on prominently branding the development interventions that they fund - they want the citizens of aid-receiving countries to know that projects are funded by an ostensibly benevolent foreign government (Sacks 2011; DFID 2012; USAID 2012). While the goal of this project branding is to improve attitudes toward the donor countries among recipient country citizens, the potential negative externality of the branding is that it might interrupt the virtuous circle in which government performance leads to legitimation of the government among citizens and to citizen compliance with the government in terms of tax payments and other behaviors, which then helps future government performance (Sacks 2011, 2012).

The idea that non-state provision of social services might undermine state legitimacy is widespread in the literature on non-governmental organizations in the developing world (Brass 2010). While nongovernmental organizations can provide services that benefit poor people in developing countries, they may do so at the expense of state legitimacy (Fowler 1991), particularly in those cases where developing country governments have explicitly tried to legitimize their rule through promises of service provision (Bratton 1989). Gubser (2002: 141) bluntly suggests that states might be "embarrassed" by other actors taking on government responsibilities. Whaites (1998) argues, from a normative perspective, that nongovernmental organizations providing grassroots services have an obligation to try to build capacity within the state to offset this risk. Lake (2010) makes a similar argument in suggesting that the obvious presence of foreign actors in the state-building process can be self-defeating. 
In this paper, we collect individual-level evidence on whether or not the presence of foreign-funded development interventions undermines citizens' confidence in their state institutions. We do so by using a survey experiment conducted on Indian citizens in which we describe a project in the health sector and vary the information that we reveal about the source of project funding. India is an appropriate case to study because the penetration of foreign aid donors is not so great that citizens will automatically assume that the project is foreign-funded and yet is large enough that citizens will not have trouble understanding the implications of the prompt. Overall, we find null results, although the point estimates are suggestive of a scenario in which awareness of a foreign role in service provision improves attitudes toward the government's general performance but reduces approval ratings for specific institutions. We provide ex post power analyses to justify the relevance of our conclusions and then discuss some likely differences between our survey experimental treatment and exposure to branded foreign aid in the field.

\section{Hypothesis}

If citizens are aware that foreign actors are providing the goods and services that national governments are supposed to provide, this may undermine confidence in the government. Because core functions are being outsourced to other countries, citizens may view their government as ineffective or irrelevant. That said, Sacks (2012) argues and finds observational evidence for the viewpoint that successful government management of foreign aid actors (at either a national or local level) may serve to demonstrate government capacity to citizens and thereby increase legitimacy. We test the initial hypothesis, that knowledge about the foreign funding and implementation of development projects will reduce government legitimacy.

\section{Methodology}


We used Amazon's Mechanical Turk to recruit a convenience sample of 1,400 respondents from India in August 2012. ${ }^{1}$ Potential subjects were offered US\$0.15 to "take a 10-minute survey in which we ask your opinions about a healthcare program in India." Respondents were required to be in India and have a 95 percent or higher approval rate for previous work done on Mechanical Turk. The survey was in English, requiring an intermediate degree of proficiency to complete.

Recruiting through Mechanical Turk means that our sample is likely to differ from a random sample of Indian respondents in several ways. As compared to the average Indian, the average respondent in our sample is more likely to be younger, highly educated, living in an urban area, and proficient in English. From this sample, we can generalize to a young Indian elite that is likely to be relatively politically engaged and also relatively likely to observe evidence of foreign sponsorship of development interventions through indirect means (e.g. news broadcasts). ${ }^{2}$

After a series of 11 demographic and background questions (including four questions about the severity of the HIV/AIDS problem in India), respondents were presented with a vignette about an HIV/AIDS prevention program. In the control condition, the vignette read as follows:

The Samastha project is a comprehensive HIV/AIDS program, involving prevention, care, support, and treatment, in the state of Karnataka, a state that exhibits high rates of HIV infection. The project's goal is to reduce transmission and the impact of HIV in selected districts, with a focus on rural areas. The Samastha project provides system strengthening at the state level and services in 13 high-HIV/AIDS prevalence districts in Karnataka.

Since the beginning of the project in 2006:

- The program increased coverage of care for children affected by HIV and AIDS to about $54.5 \%$ of the estimated 33,000 infected children in Karnataka.

- Among Karnataka's estimated 1.2 million pregnant women annually, the proportion who received counseling and testing for HIV increased from $20.1 \%$ to more than $67 \%$.

\footnotetext{
${ }^{1}$ For more on the use of Mechanical Turk in social science research, see Berinksy, Huber and Lenz (2012) and Mason and Suri (2012).

${ }^{2}$ We summarize the characteristics of the sample in the online appendix.
} 
Across four treatment conditions, we inserted a sentence following the first sentence in the vignette describing the funding and implementation of the project. The four treatments read as follows:

(1) [Foreign Funder (U.S.)] The program is supported by the government of the United States through the United States Agency for International Development (USAID).

(2) [Foreign Funder (U.S.) and Local Implementer] The program is supported by the government of the United States through the United States Agency for International Development (USAID), and is administered by the Karnataka State AIDS Prevention Society and local NGOs.

(3) [Foreign Funder (U.S.) and Foreign Implementer] The program is supported by the government of the United States through the United States Agency for International Development (USAID) and is administered by international NGOs.

(4) [Foreign Funder (Canada)] The program is supported by the government of Canada through the Canadian International Development Agency (CIDA).

The real project on which the vignette is based was jointly sponsored by the United States and Canada and jointly administered by international and local NGOs; therefore, the vignettes do not involve direct deception, although each treatment omits some information.

Immediately following the vignette, respondents were asked a series of questions about their impressions of the project. They were then asked about government performance on the issue of HIV/AIDS and asked to provide favorability ratings of several national institutions and several foreign countries. Specifically, respondents were asked whether they had a very favorable, favorable, unfavorable, or very unfavorable opinion of (1) Prime Minister Manmohamn Singh and (2) the Lok Sabha (the lower house of parliament in India), and they were asked (3) to "assess the job that the national government is doing in addressing the problem of HIV/AIDS across India" and (4) to "rate the job that your state government is doing in addressing the problem of HIV/AIDS within [the respondent's state]." For these latter two questions, they could again choose one of four answers (very poor, poor, good, and very good). Respondents also were asked, "How much do you think that foreign aid from other countries contributes to the provision of social services in India?" and could answer on a four-point scale 
(nothing; a little; some; a lot). If branded aid undermines government legitimacy, we expect

respondents in the treatment condition to rate government institutions and performance more negatively.

\section{Results}

Before looking at the results with regard to legitimacy, we first show, in the first column of Table 1, that respondents in the treatment conditions were more likely to say that foreign aid from other countries contributes a greater amount to the provision of social services. This treatment effect was significant for three of the manipulations. This significant treatment effect is evidence that the experimental manipulations conveyed the intended information about the foreign funding of development interventions and that respondents absorbed this information. ${ }^{3}$

For the two follow-up questions referring to the prime minister and the legislature, the estimated treatment effects are in the direction predicted by our main hypothesis: when respondents hear about foreign funding and implementation of a large-scale social service project, they express less favorable opinions about Prime Minister Singh and the Lok Sabha. The differences are not significant across any of the four treatment conditions, nor are they significant when all four conditions are combined $(b=-0.07$, $p<0.22$ for the prime minister; $b=0.07, p<0.17$ for the legislature) or when the three U.S. conditions are combined $(b=0.06, p<0.29$ for the prime minister; $b=0.08, p<0.14$ for the legislature). The

\footnotetext{
${ }^{3}$ The statistically significant results also suggest that respondents in the control condition were not assuming that the project was foreign funded, something that would increase the overall likelihood of a null result. In the original survey, however, we did not have a manipulation check question to collect direct evidence on this. In June 2014, we ran a new Mechanical Turk survey in which we replicated the control condition and asked a manipulation check question toward the end of the survey: Do you remember the Samastha HIV/AIDS prevention program that we described earlier? Do you remember who provided the funding for that program? (a) Indian national government; (b) Karnataka state government; (c) United States of America government; (d) Not sure / don't remember. Only 3.5 percent of respondents said that it was the U.S. government. Fifty percent of respondents assumed it was the Karnataka state government, and 21 percent assumed it was the Indian national government. One-quarter of respondents said that they were not sure or did not remember.
} 
confidence intervals in both cases are about two-thirds in negative territory and one-third in positive territory.

For the other two follow-up questions, which asked respondents to more generally assess the performance of the national and state governments in the sector where the project is occurring, we find treatment effects in the opposite direction. Across the three U.S. treatments, respondents give more credit to both the national and state governments after hearing about a U.S.-funded project. These results are not statistically significant, either individually or when combined $(b=0.06, p<0.18$ for the national government; $b=0.02, p<0.68$ for the state government), but for the national government question, about three-quarters of each confidence interval lies in positive territory. The direction of these estimated treatment effects resemble the correlations found in Sacks (2012), where citizens think more highly of their government when they also think that foreign actors are involved in social service provision. In contrast, when respondents hear about Canadian funding, the ratings of the national and state governments appear lower as compared to the control condition. The direction of these treatment effects is in line with the original hypothesis, but the uncertainty surrounding the point estimates is once again large.

Because of the small magnitude of the changes between treatment conditions, the results are not statistically significant. ${ }^{4}$ In Figure 1, we present ex-post power analyses based on the estimated treatment effects and the observed variances for the four political legitimacy variables. The plots suggest that if we had obtained an $\mathrm{N}=2,000$ sample across a single U.S.-funding treatment condition and a control group, then we would have observed statistical significance for the Lok Sabha favorability

\footnotetext{
${ }^{4}$ We tried two strategies to reduce the level of noise in our analysis. First, we estimated the treatment effects using linear regression models in which we included controls for respondents' reported gender, age, education, income and exposure to the news. The inclusion of covariates only marginally changed the estimated treatment effects and produced nearly identical p-values (results not reported). We also estimated treatment effects within relevant subgroups of respondents: those who report reading the newspaper or watching news daily, those who scored in the top-third of an index of political activity, and those who ranked HIV/AIDS as one of the most important issues facing India. In all cases, we expected to find stronger treatment effects. However, among none of these subsets of respondents was the estimated average treatment effect significant (results not reported).
} 
measure and the perceptions of national government performance measure. With a similarly divided sample of $\mathrm{N}=3,000$, we might have been able to observe a statistically significant result for the prime minister favorability measure. The very small estimated differences on the state government performance measure suggest that we would need an implausibly large survey to observe statistically significant results for that variable.

\section{Summary}

If citizens in developing countries see foreign actors fund and implement social services, this may cause them to lose confidence in the abilities or raison d'être of their own government. A decrease in legitimacy risks reducing the government's ability to collect tax revenues and otherwise extract compliance from citizens (Weber 1968; Levi and Sacks 2009; Sacks 2012). As foreign aid donors have increasingly emphasized the branding of development interventions, a loss of government legitimacy might be an unintended negative externality.

Results from a survey experiment in which citizens are told about a health intervention and randomly assigned to learn that it is either foreign-funded or not provide mixed evidence on the effects of information about foreign funding. On the one hand, particular government institutions - such as the sitting prime minister or the legislature - suffer from lower approval ratings in the treatment conditions. On the other hand, overall government performance is assessed more positively when citizens are told about foreign involvement in service provision. Further research is needed, but one explanation for this set of average treatment effects is that citizens both value the social services being provided and therefore reward the government as a whole for their provision (even if they are foreign-funded) and yet also experience some displeasure with the idea that foreigners are providing the services and so hold particular representatives of government in lower esteem. 
Although none of these results are statistically significant at conventional levels, effects from survey experimental manipulations in this particular context might be much weaker than those that would be observed in the field. Real-world branded foreign aid provides repeated exposure for those who use it or otherwise encounter it. This repeated exposure might deepen the reactions to the aid. In addition, people are likely to learn about foreign funding and implementation in sectors that they care most about. Learning about foreign involvement in issues that respondents deem most important may increase the intensity of the responses that they have to it. 


\section{Works Cited}

Bates, Robert H. and Da-Hsiang Donald Lien. 1985. “A Note on Taxation, Development and Representative Government," Politics \& Society 14(1): 53-70.

Berinsky, Adam J., Gregory A. Huber, and Gabriel S. Lenz. 2012. “Evaluating Online Labor Markets for Experimental Research: Amazon.com's Mechanical Turk," Political Analysis 20: 351-68.

Brass, Jennifer. 2010. Surrogates for Government? NGOs and the State in Kenya. Ph.D. Dissertation. University of California, Berkeley.

Bratton, Michael. 1989. "The Politics of Government-NGO Relations in Africa," World Development 17(4): 569-587.

Department for International Development (DFID). 2012. "New Logo: Flying the Flag for UK Aid," press released, 25 June, available at http://www.dfid.gov.uk/News/Latest-news/2012/New-logo-uk-aid/ (accessed 28 August 2012).

Fowler, Alan. 1991. "The Role of NGOs in Changing State-Society Relations: Perspectives from Eastern and Southern Africa," Development Policy Review 9: 53-84.

Gubser, Peter. 2002. "The Impact of NGOs on State and Non-state Relations in the Middle East," Middle East Policy 9(1): 139-48.

Lake, David. 2010. "The Practice and Theory of U.S. Statebuilding," Journal of Intervention and StateBuilding 4(3): 257-84.

Levi, Margaet. 1988. Of Rule and Revenue. Berkeley: University of California Press.

Levi, Margaret and Audrey Sacks. 2009. "Legitimating Beliefs: Concepts and Indicators," Regulation and Governance 3: 311-33.

Mason, Winter and Siddharth Suri. 2012. “Conducting Behavioral Research on Amazon's Mechanical Turk," Behavioral Research Methods 44(1): 1-23. 
Moore, Mick. 2008. "Between Coercion and Contract: Competing Narratives on Taxation and Governance," in Deborah Bräutigam, Odd-Helge Fjeldstad, and Mick Moore, eds. Taxation and State-Building in Developing Countries: Capacity and Consent. New York: Cambridge University Press, pp. 34-63.

Sacks, Audrey. 2011. Credit or Blame: Non-State Provision of Services and Political Support in Africa. Ph.D. Dissertation. University of Washington.

Sacks, Audrey. 2012. “Can Donors and Non-State Actors Undermine Citizens' Legitimating Beliefs?” World Bank Policy Research Working Paper 6158, August, Washington, D.C.

Timmons, Jeffrey F. 2005. "The Fiscal Contract: States, Taxes and Public Services," World Politics 57(4): 530-67.

United States Agency for International Development (USAID). 2012. “Branding," 19 June, available at http://www.usaid.gov/branding/ (accessed 28 August 2012).

Weber, Max. 1968. Economy and Society. Berkeley: University of California Press.

Whaites, Alan. 1998. "NGOs, Civil Society and the State: Avoiding Theoretical Extremes in Real World Issues," Development in Practice 8(3): 343-9. 


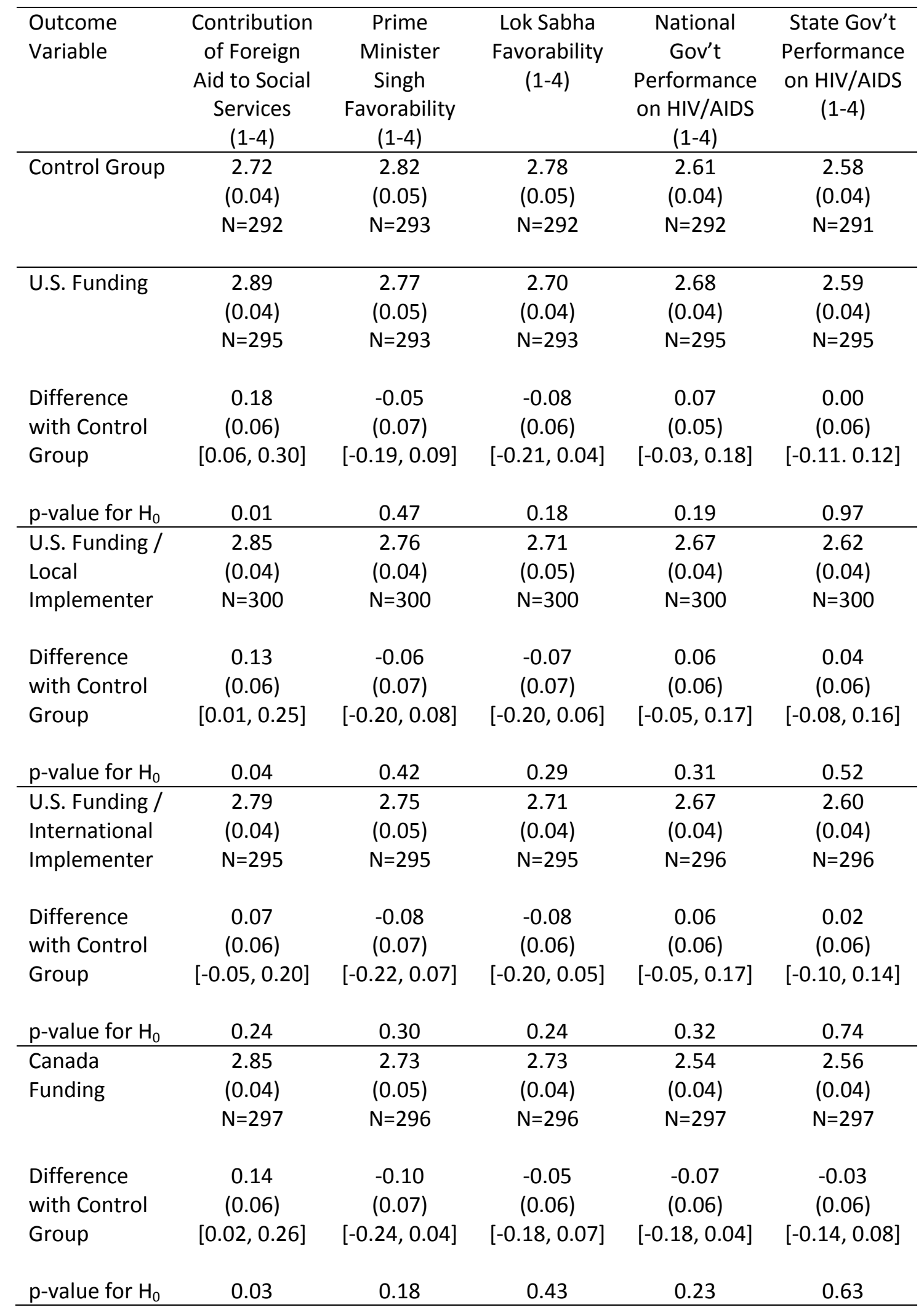

Table 1. Average Treatment Effects for Four Treatment Conditions. Standard errors in parentheses; 95-percent confidence intervals in brackets. $\mathrm{p}$-values are for two-tailed t-tests of $\mathrm{H}_{0}$ : no difference between the treatment and control groups. 

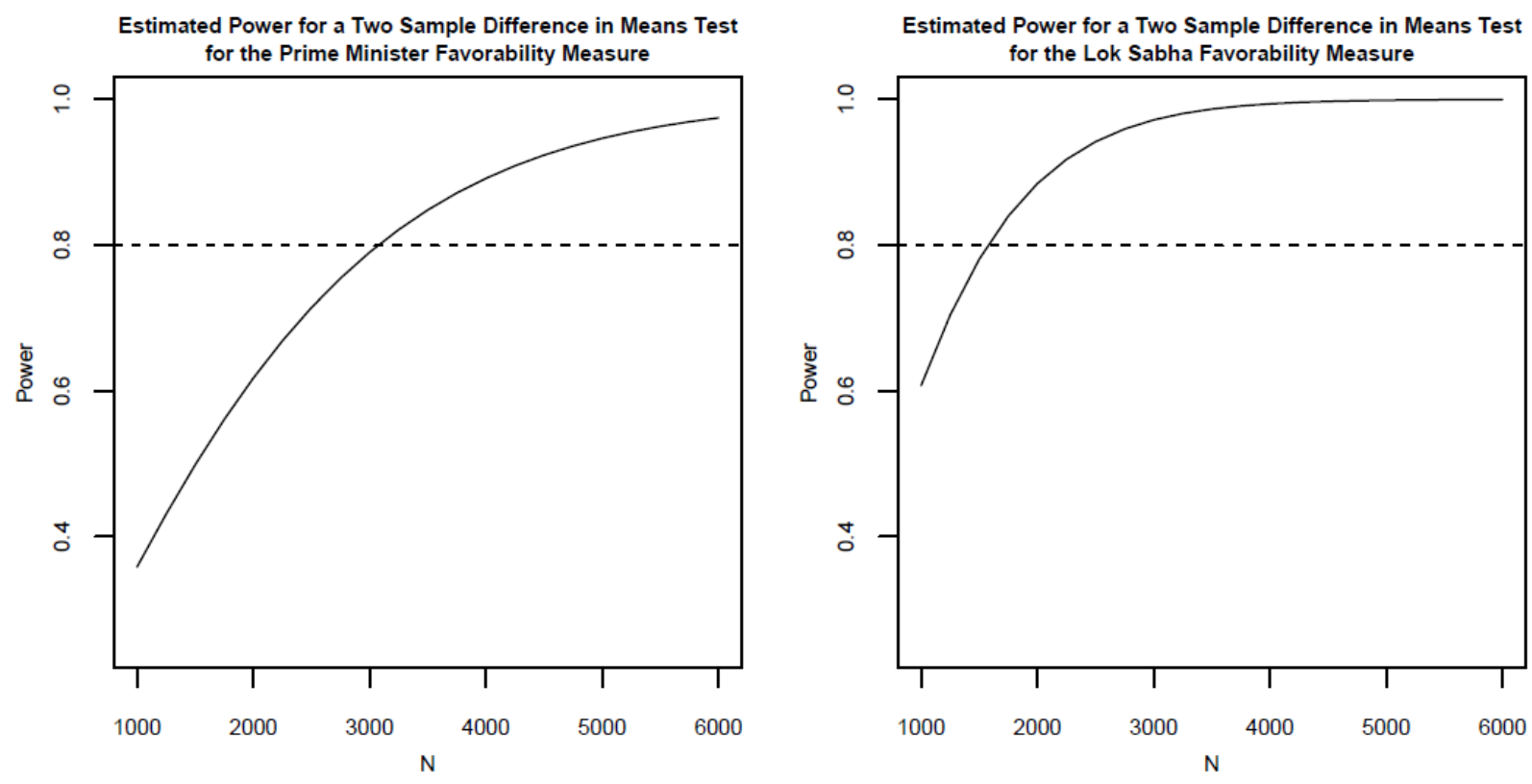

Estimated Power for a Two Sample Difference in Means Test for the National Gov't Performance Measure
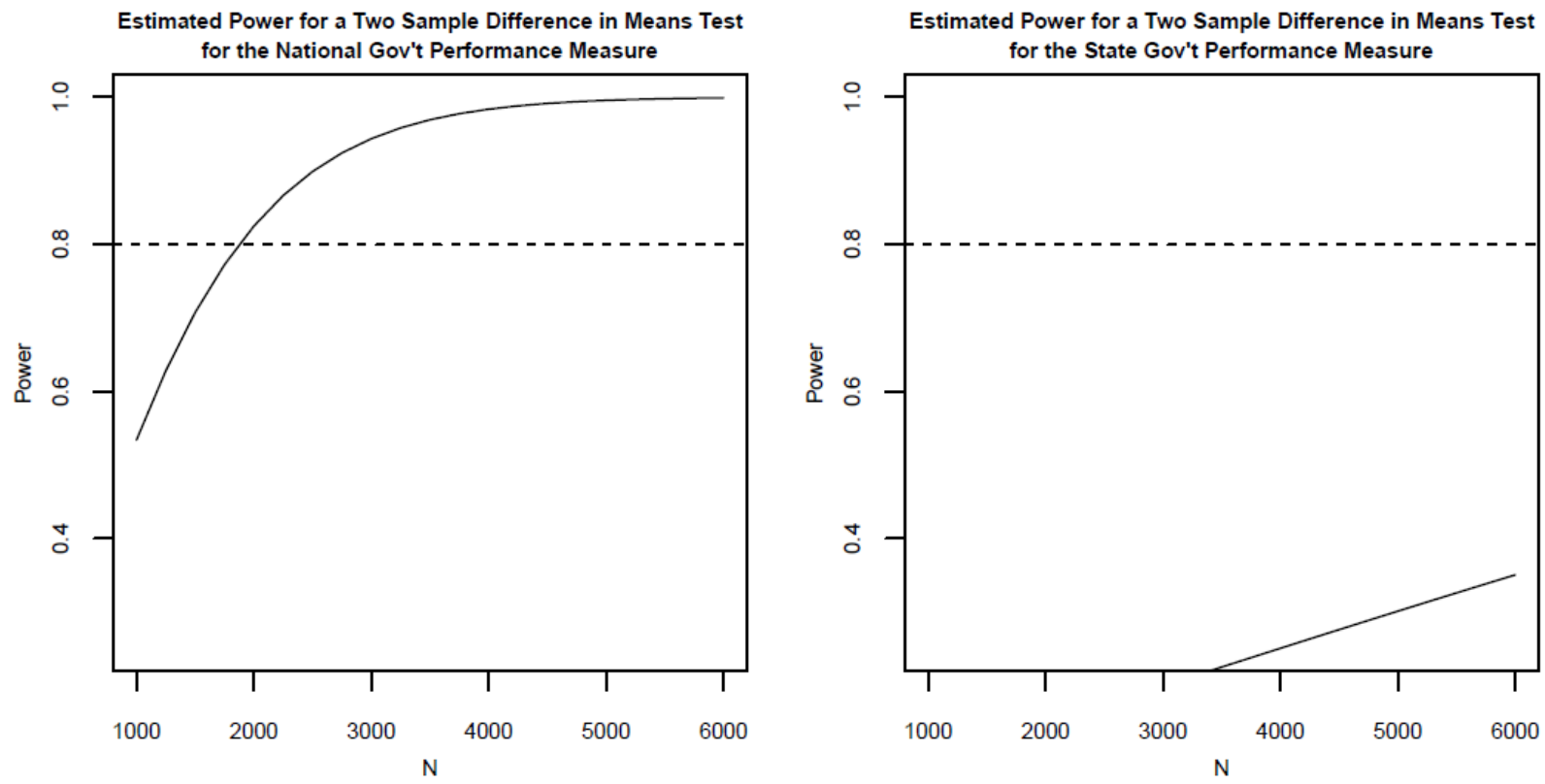

Figure 1. Power Analyses. Based on estimated standardized effect sizes from the combined U.S. conditions versus the control condition. Assuming a desired significance level of $\alpha=0.05$. 